УДК 581.524.3: $581.527 .7(470.331)$

DOI 10.18413/2658-3453-2020-2-4-260-271

\title{
СУКЦЕССИОННАЯ ДИНАМИКА ФИТОЦЕНОЗОВ С УЧАСТИЕМ ПОЛЕМОХОРОВ
}

\section{SUCCESSION DYNAMICS OF PHYTOCENOSES WITH POLEMOHORA-SPECIES}

\author{
А.А. Нотов ${ }^{1}$, В.А. Нотов ${ }^{1,2}$, Л.В. Зуева ${ }^{1}$, С.А. Иванова ${ }^{1}$ \\ A.A. Notov ${ }^{1}$, V.A. Notov ${ }^{1,2}$, L.V. Zueva ${ }^{1}$, S.A. Ivanova ${ }^{1}$ \\ ${ }^{1}$ Тверской государственный университет, \\ Россия, 170100, г. Тверь, ул. Желябова, 33 \\ ${ }^{2}$ МБОУ СОШ № 3 пос. Редкино, \\ Россия, 171261, Тверская обл., Конаковский район, пос. Редкино, ул. Диева, 33а \\ ${ }^{1}$ Tver State University, \\ 33 Zhelyabova St, Tver, 170100, Russia \\ ${ }^{2}$ Secondary School № 3, Redkino settlement, \\ 33a Dieva St, Redkino settlement, Konakovsky district, Tver region, 171261, Russia \\ E-mail: anotov@mail.ru; vnotov123@mail.ru; zuevabio2012@yandex.ru; dmitrievas@mail.ru
}

\begin{abstract}
Аннотация
В 2019-2020 гг. в Тверской области исследованы территории в окрестностях ключевых перевалочных пунктов Ржевско-Вяземского плацдарма. Изучены фитоценозы с участием полемохоров. Проанализированы сведения о динамике растительного покрова. После окончания Великой Отечественной войны на некоторых участках модельных территорий стали формироваться мелколиственные леса из Alnus incana (L.) Moench, Populus tremula L., Betula pendula Roth. и кустарниковые ивняки. Большинство полемохоров представляют группу луговых растений. На этих участках происходило постепенное выпадение полемохоров. Современный состав фитоценозов с полемохорами зависит от следующих факторов: 1) объема и состава занесенных чужеродных диаспор; 2) характера динамики ландшафтов и растительного покрова; 3) экологических особенностей отдельных видов.
\end{abstract}

Abstract

Polemohoras - alien plants that have penetrated beyond the primary area as a result of military activity. In 2019-2020, we examined the largest military cargo transshipment sites of Rzhev-Vyazemsky bridgehead in the Tver region. In places of discovery of polemohora-plants, we have described the modern vegetation cover. In addition, we tried to get information about existed in the 1940s vegetation cover. After the end of the Great Patriotic War, this model territories began to overgrow by Alnus incana (L.) Moench, Populus tremula L., Betula pendula Roth., and shrubs. As a result, small-leaved forest communities were formed in some parts of the model territories. Since most polemohora-plants are meadow species, fringes and forests communities were less suited for their conservation. Modern composition of phytocenoses with polemohora-species depend on three factors: 1) number and composition of alien diaspores; 2) dynamics of growing conditions for the period since the drift; 3 ) environmental requirements of certain species.

Ключевые слова: экология, динамика фитоценозов, сукцессии, адвентивные растения, полемохоры, Великая Отечественная война, Тверская область.

Keywords: ecology, dynamics of phytocenoses, succession, adventive plants, polemochores, Great Patriotic War, Tver region.

\section{Введение}

В связи с быстрой трансформацией природных экосистем актуальность развития инвазионной биологии в настоящее время существенно возрастает [Petrosyan et al., 2018]. Весомый вклад в выявление закономерностей функционирования экосистем с 
адвентивным компонентом может внести анализ полемохоров - видов, занесенных на новые территории в период военных действий [Sennikov, 2009; Сенников, 2012; Reshetnikova, 2016; Щербаков, Решетникова, 2017; Решетникова и др., 2018; Нотов и др., 2019a]. С момента окончания Великой Отечественной войны прошло уже три четверти века. За этот период сильно изменились ландшафты и фитоценозы, в которые попадали чужеродные растения. Особый интерес представляет изучение ключевых модельных территорий, испытавших значительное воздействие полемохорных заносов, на которых до настоящего времени сохранились сообщества с полемохорами. Их анализ не только может существенно дополнить данные о биологии и экологии адвентивных видов во вторичном ареале, но и позволит моделировать динамику трансформированных в результате массового заноса чужеродного материала фитоценозов, выявлять механизмы их функционирования в условиях происходящих сукцессионных смен.

Такие модельные территории сохранились в Тверской обл. в пределах бывшего Ржевско-Вяземского плацдарма, который в 1942-1943 гг. был важнейшим стратегическим объектом военных операций Ржевской битвы [Герасимова, 2016; Калашников, 2018]. Продолжительная оккупация, в период которой здесь были сосредоточены значительные силы армии вермахта, в огромных масштабах завозили военную технику, различные грузы, сено и фураж, способствовали формированию в районе крупных перевалочных пунктов фитоценозов с полемохорами. В ряде случаев они достаточно полно воспроизводили особенности состава и структуры некоторых среднеевропейских сообществ [Нотов, Нотов, 2019; Нотов и др., 2019а, б, 2020а, б].

Особый интерес представляет растительный покров в окрестностях пл. 208 км (Зубцовский р-н) и д. Папино (Ржевский р-н). Эти территории активно использовались армией вермахта в качестве ключевых перевалочных пунктов [Нотов и др., 2020а, б]. Цель нашей работы - анализ роли полемохорного компонента сообществ с учетом сукцессионной динамики растительного покрова на этих модельных территориях.

\section{Материал и методы исследования}

Более детально изучены две модельные территории: I - участок в районе пл. 208 км (Зубцовский р-н); II - окрестности д. Папино (между д. Медведево и пл. Рождествено) (Ржевский р-н). Каждая из них подвергалась продолжительной оккупации и в 19421943 гг. использовалась в качестве ключевого первалочного пункта. Это способствовало активному заносу полемохоров [Нотов, Нотов, 2019; Нотов и др., 2020а, б]. В настоящее время на обеих территориях формируются фрагменты вторичных мелколиственных сообществ, в которых условия произрастания полемохоров существенно изменяются.

В районе переезда у пл. 208 км Погорельский участок старого Зубцовского тракта пересекал Московско-Виндавскую железную дорогу. На нем разгружали вагоны и переправляли грузы, сено и фураж к складам и в большинство оккупированных немцами деревень бывшего Погорельского р-на [Нотов и др., 2020б]. В настоящее время в полосе отвода железной дороги сохраняются луговые сообщества, которые периодически выкашиваются работниками РЖД. Однако участки, расположенные вдоль лесозащитных полос, активно зарастают. На них формируются фрагменты мелколиственных лесных сообществ.

Деревня Папино была местом пересечения наиболее значимых маршрутов довоенного времени и периода оккупации. Через нее осуществлялась связь многих населенных пунктов с основными путями на Ржев. Здесь функционировала железнодорожная линия Ржев-Вязьма и начиналась дорога на Алешево. От Алешево к Ржеву уходили дороги через Турбаево, Збоево и через Медведево и Домашино. В южном направлении от Папино шла дорога через Пустошки, Лебедево и Артемово к ст. Осуга [Osteuropa ..., 1943]. В 1942 г. роль д. Папино как узлового транспортного пункта существенно возросла после создания немцами железнодорожной ветки Папино- 
Медведево-Мончалово и укрепления грунтовой дороги Папино-Медведево. В районе пл. Рождествено рядом с железной дорогой Ржев-Вязьма проходил участок дороги Папино-Пустошки и начиналась боковая железнодорожная ветка на Мончалово [Osteuropa ..., 1943]. Около пл. Рождествено в период оккупации производили разгрузку, сортировку, переправляли грузы в разные населенные пункты и на стратегические объекты. Железная дорога Папино-Мончалово играла ведущую роль в обеспечении боеготовности немецкой армии, подготовке и проведении боевых операций [Osteuropa ..., 1943; Герасимова, 2016; Калашников, 2018]. В послевоенное время она была демонтирована. Началось постепенное зарастание территории серольшаниками, сообществами с осиной и березой и кустарниковыми ивняками.

Фитоценозы с участием полемохоров изучены нами в 2019-2020 гг. Использованы традиционные методы флористических и геоботанических исследований [Нотов и др., 2019a, б, 2020a, б]. По материалам полевых наблюдений создана картографическая база данных, позволяющая анализировать характер распространения полемохоров, их фитоценотическую приуроченность и обилие [Нотов и др., 2019б, 2020а, б]. Регулярное посещение модельных территорий в течение всего вегетационного периода позволило выявить сезонную динамику сообществ и выявить эфемероидную фракцию полемохоров [Нотов и др., 2020a, б]. Проведена оценка устойчивости полемохоров в лесных биотопах.

Особенности экологии и фитоценологии полемохоров и специфику видового состава среднеевропейских сообществ с их участием выясняли на основе данных литературы [Mucina, 1997; Préservons ..., 2010-2020; Mucina et al., 2016; Velev, 2018]. Выявлены синтаксоны растительности, для которых анализируемые нами виды являются диагностическими. Для наглядности представления этих сведений мы указываем их синтаксономические коды [по: Mucina et al., 2016].

Направления изменения ландшафтной структуры модельных территорий выясняли на основе анализа картографических материалов разных исторических периодов, военной литературы [Топографическая ..., 1853; Osteuropa ..., 1943; Лист .., 1989; Герасимова, 2016; Калашников, 2018]. Учтены также материалы, собранные поисковыми отрядами, рассказы местных жителей. Характер трансформации ландшафтов соотнесен с общими направлениями постагрогенного преобразования растительности и почв южнотаежной подзоны России [Люри и др., 2010].

Проблема анализа сукцессионной динамики фитоценозов с участием полемохоров еще слабо разработана. Однако в связи с необходимостью выявления механизмов преобразования рудеральных и луговых фитоценозов в лесные, актуален подход, который использован при изучении естественного постагрогенного лесовосстановления [Ермолова и др., 2008; Телеснина, 2014, 2015; Телеснина, Климович, 2015]. Он основан на сопряженном анализе динамики роли основных эколого-ценотических групп (свит) растений [Смирнов и др., 2006; Ермолова и др., 2008; Телеснина, 2014] на различных стадиях демутационной сукцессии. В качестве контроля мы рассматривали типичные мелколиственные сообщества таежной зоны [Василевич, Кессель, 2017; Федорчук и др., 2006; Макарова, 2020].

\section{Результаты и их обсуждение}

На каждой модельной территории зарегистрировано значительное разнообразие полемохоров и выявлена их весомая фитоценотическая роль, что обусловлено спецификой прохождения оккупационного периода и особым статусом этих стратегических объектов в военное время [Нотов и др., 2019а, б, 2020а, б]. Здесь были сосредоточены основные силы вермахта, создавались дополнительные железнодорожные пути. В связи с активным использованием боевой конницы и конной тяги в больших объемах завозились сено и фураж, что способствовало массовому заносу семян из Средней Европы. В общей сложности на двух модельных территориях обнаружено 25 видов растений, 
распространенных преимущественно в Средней Европе. На каждой из них зарегистрировано не менее 20 видов [Нотов и др., 2020а, б].

Сопряженность встречаемости на наших модельных территориях этих видов, представляющих диагностические компоненты среднеевропейских сообществ, позволила установить определенное сходство сформировавшихся на них фитоценозов с некоторыми синтаксонами луговой растительности Центральной Европы [Нотов и др., 2019a, 2020a, б]. Это сходство усиливается благодаря наличию диагностических видов, распространенных в Центральной и Восточной Европе [Нотов и др., 2020a, б]. Некоторые из них встречаются на территории Тверской области крайне редко и в специфических местообитаниях. Нами высказано предположение о возможном полемохорном статусе в местах большого скопления полемохоров отдельных популяций, представленных в региональной флоре редких аборигенных и адвентивных видов [Нотов, Нотов, 2019; Нотов и др., 2020а, б]. На изученных модельных территориях в числе таких видов Allium angulosum, Carex hartmanii, Juncus inflexus, Salvia pratensis, Sanguisorba officinalis. Сопряженное с полемохорами распространение этих диагностических видов среднеевропейских сообществ позволило включить их в перечень модельных таксонов при анализе сукцессионной динамики фитоценозов с полемохорной фракцией (см. таблицу).

Таблица

Table

Фитоценотические особенности полемохоров на модельных территориях и в Центральной Европе

Phytocenotical features of polemochores on the model territories, and in Central Europe

\begin{tabular}{|c|c|c|c|c|c|c|c|c|c|c|c|c|c|}
\hline $\mathrm{P}$ & Лу С & Ле & Вид & FAG & \begin{tabular}{|c|}
$\mathrm{PU}$ \\
$\mathrm{B}$
\end{tabular} & GER & MOL & MUL & $\begin{array}{c}\mathrm{FE} \\
\mathrm{S}\end{array}$ & POP & $\begin{array}{l}\mathrm{PU} \\
\mathrm{R}\end{array}$ & $\mathrm{SCH}$ & EPI \\
\hline $\begin{array}{l}\mathrm{I}, \\
\mathrm{II}\end{array}$ & I & & Allium angulosum $\mathrm{L}$. & & & & MOL*, 05D** & & & & & & \\
\hline & I & & Aquilegia vulgaris L. & $\begin{array}{c}\text { FAG, } \\
02\end{array}$ & & 01 & {$[03 A] * * *$} & & & & & & \\
\hline $\mathbf{I}$, & \begin{tabular}{|l|l} 
I, & I \\
II & I \\
\end{tabular} & & $\begin{array}{l}\text { Arrhenatherum elatius } \\
\text { (L.) J. et C. Presel }\end{array}$ & & & $\begin{array}{l}\text { GER, } \\
01 \mathrm{~B}, \\
05 \mathrm{D}\end{array}$ & $\begin{array}{l}\text { MOL, 01A, } \\
{[01 F, 03 A]}\end{array}$ & & $01 \mathrm{~A}$ & & & & $02 \mathrm{C}$ \\
\hline & II & II & Carex flacca Schreb. & 02 & 01B & & \begin{tabular}{|c|} 
05A, 07A, 07D, \\
$08 \mathrm{E},[01 C]$
\end{tabular} & & $01 \mathrm{~A}$ & & & $01 \mathrm{~A}$ & $01 \mathrm{~A}$ \\
\hline & II & & $\begin{array}{l}\text { Carex hartmanii } \\
\text { Cajand. }\end{array}$ & & & & $05 \mathrm{~A}, 05 \mathrm{C}$ & & & & & $\begin{array}{l}\mathrm{SCH}, \\
03 \mathrm{~B}\end{array}$ & \\
\hline II & III I & I & Carex tomentosa $\mathrm{L}$. & & 01B & & MOL, 05A, 07D & & $01 \mathrm{~A}$ & & & & \\
\hline $\mathrm{I}$ & I & & $\begin{array}{l}\text { Chaerophyllum } \\
\text { aureum L. }\end{array}$ & & & & 03A, [01A] & $01 \mathrm{~A}$ & & & & & EPI, 02C \\
\hline & \begin{tabular}{|l|}
$\mathbf{I}$, \\
II
\end{tabular} & & $\begin{array}{l}\text { Colchicum } \\
\text { autumnale } \mathrm{L} .\end{array}$ & $03 \mathrm{~A}$ & & & $\begin{array}{c}\text { MOL, 01A, 03A } \\
{[01 \mathrm{~A}, 03 \mathrm{~A}]}\end{array}$ & & $01 \mathrm{~A}$ & $\begin{array}{c}02 \mathrm{~A}, \\
02 \mathrm{C}\end{array}$ & 01B & & \\
\hline II & II I & \begin{tabular}{l|l|l} 
I II \\
\end{tabular} & Cruciata laevipes Opiz & & & & \begin{tabular}{|l|}
$01 \mathrm{~A}$ \\
\end{tabular} & $03 \mathrm{~A}$ & & & & & EPI, 02C \\
\hline & & III & $\begin{array}{l}\text { Festuca heterophylla } \\
\text { Lam. }\end{array}$ & FAG & & $\begin{array}{l}01 \mathrm{~B}, \\
05 \mathrm{D}\end{array}$ & $01 \mathrm{~A}$ & & & & & & \\
\hline $\begin{array}{l}\mathrm{I}, \\
\mathrm{II}\end{array}$ & I & I II & $\begin{array}{l}\text { Fragaria moschata } \\
\text { Duch. }\end{array}$ & & & GER, 01 & & & & & & & \\
\hline $\begin{array}{l}\mathrm{I}, \\
\mathrm{II}\end{array}$ & $\begin{array}{ll}\text { II, } \\
\text { II }\end{array}$ & & $\begin{array}{l}\text { Heracleum } \\
\text { sphondylium L. }\end{array}$ & $02 \mathrm{~B}$ & & & $\begin{array}{l}\text { MOL, 01A, 03A, } \\
08 \mathrm{C},[01 F, 03 \mathrm{~A}]\end{array}$ & $\begin{array}{l}\text { MUL } \\
01 \mathrm{~A}\end{array}$ & $01 \mathrm{~A}$ & $02 \mathrm{~A}$ & $01 \mathrm{~B}$ & & $\begin{array}{l}02 \mathrm{~B} \\
02 \mathrm{C}, \\
03 \mathrm{~A}, \\
05 \mathrm{~A}\end{array}$ \\
\hline & II & & Juncus inflexus L. & & & & $\begin{array}{c}\text { MOL, 07A, 08E, } \\
\text { 10A, 10B }\end{array}$ & & & & & $01 \mathrm{~A}$ & \\
\hline & I & & $\begin{array}{l}\text { Meum athamanticum } \\
\text { Jacq. }\end{array}$ & & & & 03A, [01A, 03A] & & & & & & \\
\hline & I & & $\begin{array}{l}\text { Muscari botryoides (L.) } \\
\text { Mill. }\end{array}$ & & & & $03 \mathrm{~A}$ & & & & & & \\
\hline
\end{tabular}


Окончание таблицы End of table

\begin{tabular}{|c|c|c|c|c|c|c|c|c|c|c|c|c|c|}
\hline \multirow{3}{*}{\multicolumn{2}{|c|}{\begin{tabular}{c|c|c}
$\mathrm{P}$ & Лу \\
& $\mathbf{I}$
\end{tabular}}} & & \multirow[b]{2}{*}{ Вид } & \multirow[b]{2}{*}{ FAG } & \multirow{2}{*}{\begin{tabular}{|c|}
$\mathrm{PU}$ \\
$\mathrm{B}$
\end{tabular}} & \multirow[b]{2}{*}{ GER } & \multirow[b]{2}{*}{ MOL } & \multirow[b]{2}{*}{ MUL } & \multirow{2}{*}{\begin{tabular}{|c|c|} 
FE \\
S
\end{tabular}} & \multirow[b]{2}{*}{ POP } & \multirow{2}{*}{\begin{tabular}{|c|}
$\mathrm{PU}$ \\
$\mathrm{R}$ \\
\end{tabular}} & \multirow{2}{*}{$\mathrm{SCH}$} & \multirow[b]{2}{*}{ EPI } \\
\hline & & & & & & & & & & & & & \\
\hline & $\mathbf{I}$ & $\mathrm{I}$ & $\begin{array}{l}\text { Phyteuma nigrum } \\
\text { F.W.Schmidt }\end{array}$ & & & & $03 A,[03 A]$ & & & & & & \\
\hline II & $\begin{array}{l}\mathbf{I}, \\
\mathbf{I I}\end{array}$ & \begin{tabular}{l|l}
$\mathbf{I}$, & II \\
\end{tabular} & $\begin{array}{l}\text { Pimpinella major (L.) } \\
\text { Huds. }\end{array}$ & & 01B & & $\begin{array}{c}\text { MOL, 01, 01A, } \\
\text { 03A, 03B, [03A] }\end{array}$ & $01 \mathrm{~A}$ & & $02 \mathrm{~A}$ & & & $01 \mathrm{~A}$ \\
\hline & I & & $\begin{array}{l}\text { P. major var. rubra } \\
\text { (Hoppe) Fiori et Bég. }\end{array}$ & & & & 03A, 03B & & & & & & \\
\hline I & & & Poa supina Schrad. & & & & $\begin{array}{c}\text { MOL, } \\
\text { 03B, 03C, }[01 C]\end{array}$ & $\begin{array}{c}03 \mathrm{~A}, \\
04 \mathrm{~A}\end{array}$ & & & & & \\
\hline & I & \begin{tabular}{l|l} 
II & II \\
\end{tabular} & $\begin{array}{l}\text { Primula elatior }(\mathrm{L} .) \\
\text { Hill }\end{array}$ & $03 \mathrm{~A}$ & 01B & & $\begin{array}{c}\text { MOL } \\
\text { 03A, 03B [03A] }\end{array}$ & $03 \mathrm{~A}$ & & $\begin{array}{l}02 \mathrm{~A} \\
02 \mathrm{C}\end{array}$ & & & \\
\hline II & $\begin{array}{l}\text { I, } \\
\text { II } \\
\end{array}$ & II & Ptarmica vulgaris Hill. & & & & $\begin{array}{c}\text { MOL, } \\
05 \mathrm{~A}, 05 \mathrm{C}, 05 \mathrm{~F}\end{array}$ & & & & & & \\
\hline I & $\mathrm{I}$ & & Salvia pratensis L. & & & & $\begin{array}{c}01,03 \mathrm{~A}[01 F \\
03 A]\end{array}$ & & FES & & & & \\
\hline & $\mathrm{I}$ & & $\begin{array}{l}\text { Sanguisorba officinalis } \\
\text { L. }\end{array}$ & & & & $\begin{array}{l}\text { MOL, 01, 03A, } \\
05 \mathrm{~A}, 05 \mathrm{~B}, 05 \mathrm{D}\end{array}$ & & & & & $01 \mathrm{~A}$ & \\
\hline & \begin{tabular}{|l|l}
$\mathbf{I}$, & \\
II & 1 \\
\end{tabular} & $\begin{array}{l}\mathrm{I}, \\
\mathrm{II}\end{array}$ & $\begin{array}{l}\text { Trisetum flavescens } \\
\text { (L.) Beauv. }\end{array}$ & & & & $\begin{array}{c}\text { MOL, 01, 01A, } \\
\text { 01E, 03A [03A] }\end{array}$ & & & & & & \\
\hline
\end{tabular}

Примечание. Сообщества модельных территорий: $\mathrm{P}$ - рудеральные, Лу - луговые, $\mathrm{O}$ опушечные, Ле - лесные. Модельные территории: I - участок в районе пл. 208 км (Зубцовский р-н), II - окрестности д. Папино (Ржевский р-н). Жирный шрифт - значительное обилие вида. Классы растительности Европы: FAG - Carpino-Fagetea sylvaticae Jakucs ex Passarge 1968; PUB - Quercetea pubescentis Doing-Kraft ex Scamoni et Passarge 1959; GER - Trifolio-Geranietea sanguinei T. Muller 1962; MOL - Molinio-Arrhenatheretea Tx. 1937; MUL - Mulgedio-Aconitetea Hadac et Klika in Klika et Hadac 1944; FES - Festuco-Brometea Br.-Bl. et Tx. ex Soo 1947; POP - Alno glutinosae-Populetea albae P. Fukarek et Fabijanic 1968; PUR - Salicetea purpureae Moor 1958; ALN - Alnetea glutinosae Br.-Bl. et Tx. ex Westhoff et al. 1946; FRA - Franguletea Doing ex Westhoff in Westhoff et Den Held 1969; PHR Phragmito-Magnocaricetea Klika in Klika et Novak 1941; SCH - Scheuchzeriopalustris-Cariceteafuscae Tx. 1937; EPI - Epilobietea angustifolii Tx. et Preising ex von Rochow 1951 [incl. Galio-Urticetea Passarge ex Kopecky 1969]. Указаны синтаксономические коды [по: Mucina et al., 2016]: * - классов, ** - союзов, для которых данный вид является диагностическим, *** - союзов, включающих ассоциации, для которых вид имеет диагностическое значение.

Note. Communities of model territories: $\mathrm{P}$ - ruderal, Лy - meadows, $\mathrm{O}$ - fringes, Лe - forests. Classes of European vegetation: I - near the railway platform $208 \mathrm{~km}$ (Zubtsovsky district), II - near Papino (Rzhevsky district). Bold font - a significant abundance of species. Classes of European vegetation: FAG - Carpino-Fagetea sylvaticae Jakucs ex Passarge 1968; PUB - Quercetea pubescentis Doing-Kraft ex Scamoni et Passarge 1959; GER - Trifolio-Geranietea sanguinei T. Muller 1962; MOL Molinio-Arrhenatheretea Tx. 1937; MUL - Mulgedio-Aconitetea Hadac et Klika in Klika et Hadac 1944; FES - Festuco-Brometea Br.-Bl. et Tx. ex Soo 1947; POP - Alno glutinosae-Populetea albae P. Fukarek et Fabijanic 1968; PUR - Salicetea purpureae Moor 1958; ALN - Alnetea glutinosae Br.-Bl. et Tx. ex Westhoff et al. 1946; FRA - Franguletea Doing ex Westhoff in Westhoff et Den Held 1969; PHR Phragmito-Magnocaricetea Klika in Klika et Novak 1941; SCH - Scheuchzeriopalustris-Cariceteafuscae Tx. 1937; EPI - Epilobietea angustifolii Tx. et Preising ex von Rochow 1951 [incl. Galio-Urticetea Passarge ex Kopecky 1969]. We have given syntaxonomic codes [by: Mucina et al., 2016]: * - classes, $* *$ - alliances, for which this species is diagnostic, *** - alliances that include associations, for which this species have diagnostic significance.

Анализ участков модельных территорий с наиболее богатым видовым составом полемохоров, на которых лучше сохранилась структура исходных луговых и рудеральных сообществ, свидетельствует о близости их к исходным вариантам фитоценозов, которые «аккумулировали» заносимый чужеродный материал. Диаспоры преимущественно луговых растений (см. таблицу) из среднеевропейских сообществ попадали в луговые и рудеральные фитоценозы, которые были приурочены к ключевым перевалочным пунктам. Их умеренное сенокосное использование в послевоенный период способствовало сохранению основных компонентов видового состава трансформированного растительного покрова военного времени. Некоторые его луговые фрагменты могли 
достаточно полно воспроизводить характерные особенности состава некоторых среднеевропейских сообществ [Нотов и др., 2020а, б].

Полемохоры обеих модельных территорий наиболее полно представляют диагностический компонент класса Molinio-Arrhenatheretea Tx. 1937 (MOL) (cм. таблицу). Среди них Allium angulosum, Arrhenatherum elatius, Carex tomentosa, Colchicum autumnale, Heracleum sphondylium, Juncus inflexus, Pimpinella major, Poa supina, Primula elatior, Ptarmica vulgaris, Sanguisorba officinalis, Trisetum flavescens. Распространены также диагностические виды некоторых соподчиненных синтаксонов. В их числе союзы Triseto flavescentis-Polygonion bistortae Br.-B1. et Tüxen ex Marschall 1947 (MOL-03A) и Arrhenatherion elatioris Luquet 1926 (MOL-01A) [Нотов и др., 2020а, б]. Диагностические виды первого союза и сопряженных с ним ассоциаций более четко выявляются на I-й модельной территории. Диагностические компоненты второго союза и его соподчиненных синтаксонов распространены на обеих территориях (см. таблицу).

C союзом Triseto flavescentis-Polygonion bistortae в разной степени связаны Aquilegia vulgaris, Arrhenatherum elatius, Chaerophyllum aureum, Colchicum autumnale, Heracleum sphondylium, Meum athamanticum, Muscari botryoides, Phyteuma nigrum, Pimpinella major, Pimpinella major var. rubra, Primula elatior, Salvia pratensis, Sanguisorba officinalis, Trisetum flavescens (см. таблицу). Многие из них встречаются в окрестностях пл. 208 км только в луговых сообществах. С союзом Arrhenatherion elatioris и его ассоциациями сопряжены Arrhenatherum elatius, Chaerophyllum aureum, Colchicum autumnale, Cruciata laevipes, Festuca heterophylla, Heracleum sphondylium, Meum athamanticum, Pimpinella major, Salvia pratensis, Sanguisorba officinalis, Trisetum flavescens (см. таблицу). Некоторые общие для отмеченных союзов полемохоры, являющиеся диагностическими видами класса Molinio-Arrhenatheretea, часто в сообществах обеих модельных территорий могут быть доминантами и содоминатами. Среди них Arrhenatherum elatius и Pimpinella major [Нотов и др., 2019а, б, 2020а].

В ходе трансформации ландшафтов и растительного покрова обеих модельных территорий, которая происходила в послевоенный период, большая часть полемохоров по мере формирования опушечных и лесных фитоценозов исчезали. Выпадали, прежде всего, типичные луговые растения, которые являются широко распространенными компонентами среднеевропейских луговых сообществ (см. таблицу). В их числе Allium angulosum, Juncus inflexus, Meum athamanticum, Muscari botryoides, Poa supina, Salvia pratensis, Sanguisorba officinalis. Даже такой массовый и явно доминирующий в луговых и рудеральных сообществах вид, как Arrhenatherum elatius, на опушках встречается редко и необильно, а в лесных фитоценозах отсутствует.

Устойчивыми в лесных сообществах, образовавшихся на месте луговых и рудеральных фитоценозов, оказались виды с более широкой эколого-фитоценотической амплитудой. Среди них Carex flacca, Cruciata laevipes, Festuca heterophylla, Fragaria moschata, Pimpinella major, Primula elatior. Почти все они в Центральной Европе отмечены в составе диагностических компонентов сообществ зональных неморальных лесов умеренного пояса (см. таблицу) или нитрофильных фитоценозов, тяготеющих к Galio-Urticetea, которые сейчас предложено сближать с антропогенной растительностью класса Epilobietea angustifolii (EPI) [Mucina et al., 2016]. Однако большая часть отмеченных видов встречается в лесных сообществах изученных модельных территорий локально и с небольшим обилием. Только Pimpinella major paспространена в лесных и опушечных фитоценозах более или менее регулярно. В ряде случаев она может играть в них существенную фитоценотическую роль [Нотов и др., 2019а, б].

Особый интерес для анализа динамики растительного покрова и изучения этапов сукцессионных смен фитоценозов представляет модельная территория II. Она отличается большими размерами и более сложной ландшафтной структурой. На еe примере проведена реконструкция динамики растительного покрова [Нотов и др., 2020а]. 
Модельная территория II расположена в междуречье Малой Лочи и реки Лочь недалеко от их истоков. До создания Ржево-Вяземской железной дороги (1888 г.) она была связана с крупным лесоболотным массивом [Топографическая ..., 1853]. К началу периода оккупации на этом участке и в его окрестностях лесов уже не осталось. Они сохранились южнее и восточнее пл. Рождествено. Во время создания железнодорожной ветки ПапиноМедведево были уничтожены кустарниковые заросли [Osteuropa ..., 1943]. Однако в полосе отвода Ржево-Вяземской дороги, по-видимому, сохранились фрагменты лесозащитных полос с тополями, отдельные экземпляры которых встречаются и сейчас.

Ландшафты были сильно трансформированы под воздействием продолжительной оккупации и ожесточенных боев. Полностью уничтожены деревни Якимово и Бараново. В послевоенный период перестали использовать дорогу Папино-Лебедево. Железная дорога Папино-Мончалово была демонтирована. Началось постепенное зарастание открытых пространств лесами и кустарниками. Лесные сообщества и ивняки стали формироваться, прежде всего, около русел рек Лочь, Малая Лоча и ручьев, вдоль которых исходно оставались фрагменты сероольшаников. Рядом с сохранившимися лесными массивами образовывались молодые березово-осиновые леса. В луговых и опушечных фитоценозах постепенно усиливалась роль компонентов рудеральных сообществ, укреплялись позиции Calamagrostis epigeios (L.) Roth. В настоящее время растительный покров участка между переездом Папино и пл. Рождествено очень мозаичен и включает луговые, рудеральные, лесные, опушечные и болотные фитоценозы.

Полемохоры зарегистрированы в каждом из отмеченных типов сообществ. Однако их фитоценотическая роль очень различна. Фитоценозы с их участием разнообразны по структуре и видовому составу, приурочены к экотопам, в разной степени связанным с железной дорогой Ржев-Вязьма и бывшей грунтовой дорогой Папино-Пустошки.

В настоящее время на железнодорожной насыпи Ржево-Вяземской железной дороги и по ее склонам представлены рудеральные и луговые сообщества с полемохорами и сорными видами, в которых доминирует Arrhenatherum elatius. Этот вид обилен также в луговых ассоциациях вдоль склонов насыпи, местами отмечен в опушечных и лесных фитоценозах. В луговых сообществах модельной территории нередко доминирует Pimpinella major, местами обильны Ptarmica vulgaris, Trisetum flavescens, встречаются Heracleum sphondylium, Primula elatior, Cruciata laevipes, Carex flacca, Carex tomentosa.

Лесные и опушечные сообщества с полемохорами сформировались также на месте защитных древесных насаждений у железной дороги Ржев-Вязьма, вдоль зарастающих насыпей запасных железнодорожных путей. Лесообразующими породами в этих лесных фитоценозах являются береза, осина, серая ольха, редко встречается ель, на некоторых участках много ивы козьей. Вдоль русла реки Лочь и в наиболее сырых местах рядом с воронками от снарядов обильна серая ольха. Преобладают нитрофильно-травяные варианты мелколиственных сообществ смешанного состава, в ряде случаев встречаются осинники и сероольшаники. В их травяном ярусе обычны Pimpinella major, местами обильны Primula elatior, Cruciata laevipes, Carex flacca. В ольшаниках и осинниках с полемохорами большинство обычных для Восточной Европы и занесенных полемохорных луговых растений замещено аборигенными видами, характерными для союза Alnion incanae Pawlowski et al. 1928. На опушках иногда встречаются ассоциации с доминированием Chamaenerion angustifolium (L.) Scop. В них весьма устойчивы Pimpinella major, Ptarmica vulgaris. К опушкам иногда примыкают заболоченные участки, в которых обнаружены Ptarmica vulgaris, Carex tomentosa, Cruciata laevipes.

В настоящее время в пределах модельной территории II спектр сообществ с участием полемохоров очень широкий. В них достаточно полно представлены диагностические виды синтаксонов среднеевропейской растительности. Среди них виды, характерные для класса Galio-Urticetea, союзов Arrhenatherion elatioris и Aegopodion podagrariae Tx. 1967 [Mucina, 1997; Préservons ..., 2010-2020; Mucina et al., 2016; Velev, 
2018]. В сообществах в окрестностях д. Папино встречаются также диагностические виды классов, к которым относят эти союзы [Нотов и др., 2020а]. С учетом тенденций трансформации ландшафтов и сукцессионной динамики растительного покрова можно предположить, что многие занесенные полемохоры вначале функционировали как компоненты луговых и рудеральных сообществ [Нотов и др., 2019а, б, 2020а, б]. Фитоценозы, сформировавшиеся в местах массового заноса чужеродного материала, были похожи по своему составу на сообщества союза Arrhenatherion elatioris. Об этом свидетельствует и высокая репрезентативность видов диагностического компонента класса Molinio-Arrhenatheretea. По мере формирования нитрофильных ассоциаций с различной степенью антропогенной трансформации, некоторые из них смогли сохранить устойчивость в лесных фитоценозах. Прежде всего, это Pimpinella major, Ptarmica vulgaris, Primula elatior, Cruciata laevipes. В пределах вторичного ареала эти виды достаточно полно реализовали свой адаптивный потенциал.

Современный состав фитоценозов с полемохорами зависит от объема и состава занесенных чужеродных диаспор, специфики динамики ландшафтов и растительного покрова и экологических особенностей видов. Формирование лесных сообществ с полемохорами, осуществляемое в ходе демутационных сукцессий, в некоторой степени сходно с процессами естественного постагрогенного лесовосстановления [Ермолова и др., 2008; Телеснина, 2014, 2015; Телеснина, Климович, 2015]. Происходит постепенное замещение сорно-рудеральных, луговых нитрофильных и мезофильных видов опушечными и бореальными видами. В ряде случаев в этих сменах значимо участие представителей неморальной группы. Оно в большей степени проявляется при наличии в окрестностях сообществ с более типичной для осинников и ольшаников таежной зоны структурой и составом [Василевич, Кессель, 2017; Федорчук и др., 2006; Макарова]. В этом отношении показательны сообщества с осиной в окрестностях пл. Рождествено.

\section{Заключение}

В местах ключевых перевалочных пунктов Ржевско-Вяземского плацдарма сформировались фитоценозы с полемохорами, которые обнаруживают сходство с некоторыми среднеевропейскими сообществами. В настоящее время на территории заброшенных и неиспользуемых участков на месте луговых и рудеральных сообществ с полемохорами образуются вторичные мелколиственные леса. Состав и структура компонентов современной растительности зависят от объема занесенных чужеродных диаспор, характера динамики ландшафтов и сукцессионных смен, экологических особенностей видов.

Растительный покров в окрестностях изученных модельных территорий уникальная модель для сопряженного анализа механизмов трансформации фитоценозов с участием полемохоров. Дальнейшие исследования будут способствовать разработке подходов к оценке адаптивных потенций среднеевропейских видов во вторичном ареале.

\section{Благодарности}

Работа выполнена при финансовой поддержке гранта РФФИ № 18-04-01206. Авторы выражают глубокую благодарность А.В. Халиманчуку (Военно-исторический поисковый чентр «Память 29 армии»), руководителю поискового отряда «Звезда» В.В. Стррельникову за ценные консультации и Е.А. Лубниной (ГБУЗ ГКБ им. М.П. Кончаловского ДЗМ) за помощьь в организачии исследований. Мы очень признательны С.P. Майорову (Московский государственный университет им. М.В. Ломоносова) за проверку правильности определения гербарного материала. 


\section{Список литературы}

1. Василевич В.И., Кессель Д.С. 2017. Видовое разнообразие сообществ березовых и сероольховых лесов Северо-Запада России. Ботанический журнал, 102 (5): 585-597. DOI $10.1134 / \mathrm{S} 0006813617050015$.

2. Герасимова С.А. 2016. «Я убит подо Ржевом»: трагедия Мончаловского «котла». М., Яуза, 377 с.

3. Ермолова Л.С., Гульбе А.Я., Гульбе Я.И. 2008. Возрастные изменения травяного покрова сероольшаников, формирующихся на бывших сельскохозяйственных угодьях. Актуальные проблемы лесного комплекса, 21 (3): 72-75.

4. Калашников А.С. 2018. 77-я годовщина начала первой Ржевско-Вяземской операции. URL: https://ok.ru/osugagrupp/topic/68643282679231. (дата обращения: 18 ноября 2020).

5. Лист О-36-141 Ржев 1989. В атласе: Топографические карты СССР (1:100000): Ленинградская, Новгородская, Вологодская и Тверская области. 1975-1990.

6. Люри Д.И., Горячкин С.В., Караваева Н.А., Денисенко Е.А., Нефедова Т.Г. 2010. Динамика сельскохозяйственных земель России в XX веке и постагрогенное восстановление растительности и почв. М., ГЕОС, $416 \mathrm{c.}$

7. Макарова М.А. 2020. Осиновые (Populus tremula) леса Северо-Западного Приладожья. Ботанический журнал, 105 (10): 957-980. DOI 10.31857/S0006813620100063.

8. Нотов А.А., Нотов В.А. 2019. О полемохорных и аборигенных популяциях некоторых видов флоры Тверской области. Вестник Тверского государственного университета. Биология и экология, 4 (56): 84-102. DOI 10.26456/vtbio122.

9. Нотов А.А., Нотов В.А., Зуева Л.В., Андреева Е.А. 2019а. Полемохоры Тверской области и проблема биологических инвазий. Разнообразие растительного мира, 3 (3): 22-27. DOI 10.22281/2686-9713-2019-3-39-44.

10. Нотов А.А., Нотов В.А., Зуева Л.В., Андреева Е.А., Мидоренко Д.А. 2019б. О распространении некоторых растений-полемохоров в Тверской области. Вестник Тверского государственного университета. Биология и экология, 3 (55): 161-175. DOI 10.26456/vtbio109.

11. Нотов А.А., Нотов В.А., Иванова С.А., Зуева Л.В., Мидоренко Д.А. 2020а. Cruciata laevipes в экосистемах Тверской области. Вестник Тверского государственного университета. Биология и экология, 3 (59): 74-85. DOI 10.26456/vtbio161.

12. Нотов А.А., Нотов В.А., Иванова С.А., Зуева Л.В., Мидоренко Д.А. 2020б. Экология и фитоценология Primula elatior в Тверской области. Вестник Тверского государственного университета. Биология и экология, 2 (58): 94-104. DOI 10.26456/vtbio152.

13. Решетникова Н.М., Щербаков А.В., Фадеева И.Ф. 2018. Материалы к флоре «Красного бора» - уникальной охраняемой территории Смоленской области. Вестник Тверского государственного университета. Биология и экология, 4: 160-190. DOI 10.26456/vtbio37.

14. Сенников А.Н. 2012. Горькая память земли: Растения-полемохоры в Восточной Фенноскандии и Северо-Западной России. $B$ кн.: Проблемы изучения адвентивной и синантропной флор России и стран ближнего зарубежья. Ижевск, ИИКИ: 182-185.

15. Смирнов В.Э., Ханина Л.Г., Бобровский М.В. 2006. Обоснование системы экологоценотических групп видов растений лесной зоны Европейской России на основе экологических шкал, геоботанических описаний и статистического анализа. Бюллетень Московского общества испытателей природы. Отдел биологический, 111 (2): 36-47.

16. Телеснина В.М. 2014. Особенности динамики растительного покрова при естественном постагрогенном лесовосстановлении (флористический состав и экологические группы растений). Бюллетень Брянского отделения Русского ботанического общества, 1 (3): 55-66.

17. Телеснина В.М. 2015. Постагрогенная динамика растительности и свойств почвы в ходе демутационной сукцессии в южной тайге. Лесоведение, 4: 293-306.

18. Телеснина В.М., Климович Е.Ю. 2015. Особенности постагрогенной динамики растительности в южной тайге (на примере Костромской области). Бюллетень Московского общества испытателей природы. Отдел биологический, 120 (3): 47-59.

19. Топографическая межевая карта Тверской губернии Ржевского уезда. 1853. М., РГО, 12.

20. Федорчук В.Н., Нешатаев В.Ю., Кузнецова М.Л. 2005. Лесные экосистемы СевероЗападных районов России. Типология, динамика, хозяйственные особенности. СПб., СПбНИИЛХ, 382 c. 
21. Щербаков А.В., Решетникова Н.М. 2017. Где искать растения-полемохоры в Смоленской области? B кн.: Изучение адвентивной и синантропной флор России и стран ближнего зарубежья: итоги, проблемы, перспективы. М.-Ижевск, Институт компьютерных исследований: $134-137$.

22. Mucina L. 1997. Conspectus of classes of the European vegetation. Folia Geobotanica et Phytotaxonomica, 32 (2): 117-172. DOI 10.1007/BF02803738.

23. Mucina L., Bueltmann H., Dierssen K., Theurillat J.P., Raus T., Carni A., Sumberova K., Willner W., Dengler J., Garcia R.G., Chytry M., Hajek M., Di Pietro R., Iakushenko D., Pallas J., Daniels F.J.A., Bergmeier E., Santos Guerra A., Ermakov N., Valachovic M., Schaminee J.H.J., Lysenko T., Didukh Y.P., Pignatti S., Rodwell J.S., Capelo J., Weber H.E., Solomeshch A., Dimopoulos P., Aguiar C., Hennekens S.M., Tichy L 2016. Vegetation of Europe: hierarchical floristic classification system of vascular plant, bryophyte, lichen, and algal communities. Applied Vegetation Science, 19 (1): 3-264. DOI 10.1111/avsc. 12257.

24. Osteuropa 1:300000: Deutsche Heereskarte. 1943. Blatt Nr. X 57 Rshew. Available at: http://maps.mapywig.org/m/German_maps/series/300K_UvM/X57_Rshew_VI.1943.jpg. （accessed: 16 November 2020).

25. Petrosyan V.G., Khlyap L.A., Reshetnikov A.N., Krivosheina M.G., Dergunova N.N., Osipov F.A., Dgebuadze Y.Y., Morozova O.V. 2018. Alien species in the Holarctic. Russian Journal of Biological Invasions, 9 (4): 374-381.

26. Préservons la Nature. 2010-2020. Available at: https://www.preservons-la-nature.fr/flore/ famille/index.html. (accessed 16 November 2020).

27. Reshetnikova N.M. 2016. The way of emergence of some Western European plant species in Kaluga oblast - the pathway of the German army in 1941-1943. Russian Journal of Biological Invasions, 7 (1): 62-68. DOI 10.1134/S2075111716010082.

28. Sennikov A.N. 2009. Ado Haare (1934-2008), a prominent Estonian naturalist in Russia, and his Theory of Wonderglades. Memoranda Soc. Fauna Flora Fennica, 85: 61-67.

29. Velev N. 2018. Arrhenatheretalia elatioris uncritical checklist of Europe. Phytologia Balcanica, 24 (1): 99-147.

\section{References}

1. Vasilevich V.I., Kessel D.S. 2017. Species diversity of birch and grey alder forest communities of Northwest Russia. Botanical journal, 102 (5): 585-597. DOI 10.1134/S0006813617050015.957-980. (in Russian)

2. Gerasimova S.A. 2016. "Ya ubit podo Rzhevom": tragediya Monchalovskogo "kotla" ["I was killed near Rzhev": the tragedy of Monchalovskogo "boiler"]. Moscow, Yauza, 377 p.

3. Ermolova L.S., Gul'be A.Ya., Gul'be Ya.I. 2008. Vozrastnyye izmeneniya travyanogo pokrova serool'shanikov, formiruyushchikhsya na byvshikh sel'skokhozyaystvennykh ugod'yakh [Age-related changes in the grass cover of gray sandstones formed on former agricultural land]. Aktual'nyye problemy lesnogo kompleksa, 21 (3): 72-75.

4. Kalashnikov A.S. 2018. 77-ya godovshchina nachala pervoy Rzhevsko-Vyazemskoy operatsii [77th anniversary of the first Rzhev-Vyazma operation]. Available at: https://ok.ru/osugagrupp/topic/68643282679231. (accessed: 18 November 2020).

5. List O-36-141 Rzhev 1989. In: Topograficheskiye karty SSSR (1:100000): Leningradskaya, Novgorodskaya, Vologodskaya i Tverskaya oblasti. 1975-1990 [Topographic maps of the USSR (1:100000): Leningrad, Novgorod, Vologda and Tver regions. 1975-1990].

6. Lyuri D.I., Goryachkin S.V., Karavaeva N.A., Denisenko E.A., Nefedova T.G. 2010. Dynamics of agricultural lands of Russia in XX century and postagrogenic restoration of vegetation and soils. Moscow, GEOS, 416 p. (in Russian)

7. Makarova M.A. 2020. Aspen (Populus tremula) forests of the North-Western Ladoga region. Botanical journal, 105 (10): 957-980. DOI 10.31857/S0006813620100063. (in Russian)

8. Notov A.A., Notov V.A. 2019. On polemochorous and native populations of some species in the flora of Tver region. Herald of Tver State University. Biology and Ecology, 4 (56): 84-102. DOI 10.26456/vtbio122. (in Russian) 
9. Notov A.A., Notov V.A., Zueva L.V., Andreeva E.A. 2019a. Polemochores of the Tver region and the problem of biological invasions. Diversity of plant world, 3 (3): 22-27. DOI 10.22281/26869713-2019-3-39-44. (in Russian)

10. Notov A.A., Notov V.A., Zueva L.V., Andreeva E.A., Midorenko D.A. 2019б. On distribution of some polemochores plants in Tver region. Herald of Tver State University. Biology and Ecology, 3 (55): 161-175. DOI 10.26456/vtbio109. (in Russian)

11. Notov A.A., Notov V.A., Ivanova S.A., Zueva L.V., Midorenko D.A. 2020a. Cruciata laevipes in ecosystems of Tver region. Herald of Tver State University. Biology and Ecology, 3 (59): 74 85. DOI 10.26456/vtbio161. (in Russian)

12. Notov A.A., Notov V.A., Ivanova S.A., Zueva L.V., Midorenko D.A. 2020б. Ecology and phytocenology of Primula elatior in the Tver region. Herald of Tver State University. Biology and Ecology, 2 (58): 94-104. DOI 10.26456/vtbio152. (in Russian)

13. Reshetnikova N.M., Shcherbakov A.V., Fadeeva I.A. 2019. On the flora of "Krasny Bor", a unique protected area of the Smolensk region. Herald of Tver State University. Biology and Ecology, 4: 160-190. DOI 10.26456/vtbio37. (in Russian)

14. Sennikov A.N. 2012. Gor'kaya pamyat' zemli: Rasteniya-polemokhory v Vostochnoy Fennoskandii i Severo-Zapadnoy Rossii [Memories of war times: war-time plant immigrants (polemochores) in East Fennoscandia and North-West Russia]. In: Problemy izucheniya adventivnoy i sinantropnoy flor Rossii i stran blizhnego zarubezh'ya [Problems of studying the adventive and synanthropic flora of Russia and neighboring countries]. Izhevsk, IIKI: 182-185.

15. Smirnov V.E., Khanina L.G., Bobrovsky M.V. 2006.Validation of the ecological-coenotical groups of vascular plant species for European Russian forests on the basis of ecological indicator values, vegetation releves and statistical analysis. Bulletin of Moscow Society of Naturalists. Biological series, 111 (2): 36-47. (in Russian)

16. Telesnina V.M. 2014. Vegetation dynamic by natural post-agrogenic reafforestation (floristic composition and ecological groups of plants). Bulletin of Bryansk Department of Russian botanical society, 1 (3): 55-66. (in Russian)

17. Telesnina V.M. 2015. Postagrogenic dynamics of vegetation and soil properties during demutational succession in south taiga. Russian Journal of Forest Science (Lesovedenie), 4: 293-306. (in Russian)

18. Telesnina V.M., Klimovich E.Yu. 2015. Specific of post-agrogenic vegetation dynamic in south taiga (Kostroma regoin). Bulletin of Moscow Society of Naturalists. Biological series, 120 (3): 47-59. (in Russian)

19. Topograficheskaya mezhevaya karta Tverskoy gubernii Rzhevskogo uyezda 1853 [Topographic boundary map of the Tver guberniya: Rzhev uyezd 1853]. Moscow, RGO, 12 p.

20. Fedorchuk V.N., Neshataev V.Yu., Kuznetsova M.L. 2005. Lesnyye ekosistemy SeveroZapadnykh rayonov Rossii. Tipologiya, dinamika, khozyaystvennyye osobennosti [Forest ecosystems of the North-Western regions of Russia. Typology, dynamics, forest managament features]. SaintPetersburg, St. Petersburg forestry research Institute, $382 \mathrm{p}$.

21. Shcherbakov A.V., Reshetnikova N.M. 2017. Gde iskat' rasteniya-polemokhory v Smolenskoy oblasti? [Where we can find the plants-polemochores in the Smolensk region?]. In: Izucheniye adventivnoy i sinantropnoy flor Rossii i stran blizhnego zarubezh'ya: itogi, problemy, perspektivy [Study of adventive and synanthropic flora in Russia and neighboring countries: results, problems, prospects]. Moscow-Izhevsk, Institut komp'yuternykh issledovaniy: 182-185.

22. Mucina L. 1997. Conspectus of classes of the European vegetation. Folia Geobotanica et Phytotaxonomica, 32 (2): 117-172. DOI 10.1007/BF02803738.

23. Mucina L., Bueltmann H., Dierssen K., Theurillat J.P., Raus T., Carni A., Sumberova K., Willner W., Dengler J., Garcia R.G., Chytry M., Hajek M., Di Pietro R., Iakushenko D., Pallas J., Daniels F.J.A., Bergmeier E., Santos Guerra A., Ermakov N., Valachovic M., Schaminee J.H.J., Lysenko T., Didukh Y.P., Pignatti S., Rodwell J.S., Capelo J., Weber H.E., Solomeshch A., Dimopoulos P., Aguiar C., Hennekens S.M., Tichy L 2016. Vegetation of Europe: hierarchical floristic classification system of vascular plant, bryophyte, lichen, and algal communities. Applied Vegetation Science, 19 (1): 3-264. DOI 10.1111/avsc.12257.

24. Osteuropa 1:300000: Deutsche Heereskarte. 1943. Blatt Nr. X 57 Rshew. Available at: http://maps.mapywig.org/m/German_maps/series/300K_UvM/X57_Rshew_VI.1943.jpg. （accessed: 16 November 2020). 
25. Petrosyan V.G., Khlyap L.A., Reshetnikov A.N., Krivosheina M.G., Dergunova N.N., Osipov F.A., Dgebuadze Y.Y., Morozova O.V. 2018. Alien species in the Holarctic. Russian Journal of Biological Invasions, 9 (4): 374-381.

26. Préservons la Nature. 2010-2020. Available at: https://www.preservons-la-nature.fr/flore/ famille/index.html. (accessed 16 November 2020).

27. Reshetnikova N.M. 2016. The way of emergence of some Western European plant species in Kaluga oblast - the pathway of the German army in 1941-1943. Russian Journal of Biological Invasions, 7 (1): 62-68. DOI 10.1134/S2075111716010082.

28. Sennikov A.N. 2009. Ado Haare (1934-2008), a prominent Estonian naturalist in Russia, and his Theory of Wonderglades. Memoranda Soc. Fauna Flora Fennica, 85: 61-67.

29. Velev N. 2018. Arrhenatheretalia elatioris uncritical checklist of Europe. Phytologia Balcanica, 24 (1): 99-147.

Поступила в редакиию 07.12.2020

\section{Ссылка для цитирования статьи}

For citation

Нотов А.А., Нотов В.А., Зуева Л.В., Иванова С.А. 2020. Сукцессионная динамика фитоценозов с участием полемохоров. Полевой журнал биолога, 2 (4): 260-271. DOI 10.18413/2658-3453-2020-2-4-260-271

Notov A.A., Notov V.A., Zueva L.V., Ivanova S.A. 2020. Succession dynamics of phytocenoses with polemohora-species. Field Biologist Journal, 2 (4): 260-271. DOI 10.18413/2658-3453-2020-2-4260-271 (in Russian) 